\title{
A língua brasileira de sinais como instrumento para inserção do surdo nas instituições de ensino
}

\author{
The brazilian sign language as an instrument for the insertion of the deaf in educational \\ institutions
}
La lengua de signos brasileña como instrumento para la inserción de sordos en instituciones educativas

Gilberto de Souza ${ }^{1,3 *}$, Adriana de Souza Couto ${ }^{2}$, Isabela Maria Teixeira de Oliveira ${ }^{2}$, Daniella Guimarães da Cunha ${ }^{2}$, Andréia Andrade dos Santos ${ }^{1}$, Alessandra Mara de Sousa ${ }^{3}$, Samyra Giarola Cecílio $^{1}$, Juliana de Lourdes Silva ${ }^{1}$, Regina Aparecida de Melo Bagnolli ${ }^{1}$, Marco Aurélio Teixeira de Andrade ${ }^{4}$.

\section{RESUMO}

Objetivo: O objetivo principal deste trabalho é verificar como se dá a inclusão do aluno surdo nas instituições de ensino. Para os alcances dos objetivos propostos será realizada uma revisão narrativa da literatura. Revisão bibliográfica: A Constituição Federal de 1988 diz que todos são iguais perante a lei, não podendo haver distinção de qualquer natureza, sendo garantidos o direito à vida, à liberdade, à igualdade, à segurança e à propriedade, enfatizando também a proibição de qualquer tipo de discriminação. Dentre a legislação que permeia a comunidade surda, a Lei 10.436/2002 e o Decreto 5.626/2005, são considerados os principais marcos da luta pelos direitos desses indivíduos. A Lei 12.319/2010, que regulamenta a profissão de Tradutor e Intérprete da Língua Brasileira de Sinais (ILS), é de extrema relevância para que se promova uma inclusão efetiva do surdo nos âmbitos sociais. Considerações finais: Apesar de existirem diversas legislações que favorecem a inclusão da pessoa surda, ainda a muito que se conquistar para a efetivação dos direitos desses indivíduos, sendo o ILS um agente imprescindível no processo de inclusão e para um efetivo aprendizado.

Palavras-chave: Comunicação não verbal, Surdez, Língua de sinais, Inclusão educacional.

\section{ABSTRACT}

Objective: The main objective of this work is to verify how deaf students are included in educational institutions. To achieve the proposed objectives, a narrative review of the literature will be carried out. Bibliographical review: The Federal Constitution of 1988 says that everyone is equal before the law, and there can be no distinction of any kind, being guaranteed the right to life, freedom, equality, security and property, also emphasizing the prohibition of any type of discrimination. Among the legislation that permeates the deaf community, Law 10.436 / 2002 and Decree 5.626 / 2005, are considered the main milestones of the struggle for the rights of these individuals. Law 12.319/2010, which regulates the profession of Translator and Interpreter of the Brazilian Sign Language (ILS), is extremely relevant for promoting an effective inclusion of the deaf in social spheres. Final considerations: Although there are several laws that favor the inclusion of the deaf person, there is still much to be achieved for the realization of the rights of these individuals, the ILS being an essential agent in the inclusion process and for effective learning.

Keywords: Nonverbal communication, People with hearing loss, Sign language, Educational inclusion.

\footnotetext{
${ }^{1}$ Centro Universitário Presidente Tancredo de Almeida Neves (UNIPTAN), São João del Rei - MG.

*E-mail: gilbertounifenas@yahoo.com.br

2 Universidade José do Rosário Vellano (UNIFENAS), Divinópolis - MG.

3 Universidade Federal de São João del Rei (UFSJ), Divinópolis - MG.

${ }^{4}$ Universidade Federal de São João del Rei (UFSJ), São João del Rei - MG.
} 


\section{RESUMEN}

Objetivo: El objetivo principal de este trabajo es verificar cómo se incluye a los estudiantes sordos en las instituciones educativas. Para lograr los objetivos propuestos, se realizará una revisión narrativa de la literatura. Revisión bibliográfica: La Constitución Federal de 1988 dice que todos son iguales ante la ley, y no puede haber distinción de ningún tipo, garantizándose el derecho a la vida, la libertad, la igualdad, la seguridad y la propiedad, y también enfatiza la prohibición de cualquier tipo de discriminación Entre la legislación que impregna a la comunidad sorda, la Ley 10.436 / 2002 y el Decreto 5.626 / 2005, se consideran los principales hitos de la lucha por los derechos de estas personas. La Ley 12.319 / 2010, que regula la profesión de traductor e intérprete de la lengua de signos brasileña (ILS), es extremadamente relevante para promover una inclusión efectiva de los sordos en las esferas sociales. Consideraciones finales: Aunque existen varias leyes que favorecen la inclusión de la persona sorda, aún queda mucho por lograr para la realización de los derechos de estas personas, siendo el ILS un agente esencial en el proceso de inclusión y para un aprendizaje efectivo.

Palabras clave: Comunicación no verbal, Sordera, Lenguaje de señas, Inclusión educativa.

\section{INTRODUÇÃO}

A surdez pode ser caracterizada como uma diminuição da acuidade e da percepção auditivas, que por sua vez podem dificultar a aquisição da linguagem oral. Num conceito biomédico, a surdez pode ser entendida como a perda da sensibilidade auditiva, com redução da percepção sonora, sendo classificada em dois grupos principais: a surdez de condução e a surdez neurossensorial. A de condução é a menos comum e afeta o ouvido externo ou médio, acontecendo no momento em que as ondas do fenômeno acústico não são bem conduzidas do ouvido externo para o ouvido interno. A neurossensorial é a mais comum e ocorre quando a cóclea não consegue converter corretamente a energia mecânica da vibração do som em energia elétrica, que será transmitida ao cérebro (LEVINO DA et al., 2013).

De acordo com o Decreto 5.626/2005 o aluno surdo passa a ter direito de acesso às escolas e/ou classes bilíngues em que a LIBRAS é utilizada como meio de comunicação, de ensino e de aprendizagem. Nesse contexto, a Língua Portuguesa é utilizada como segunda língua, não sendo mais o principal meio de comunicação, ensino e aprendizagem ofertado nesses espaços escolares (BRASIL, 2005).

Embasados na Lei 10.436/2002 e no decreto 5.626/2005 a criança surda tem o direito a ser matriculada em uma turma de escola comum junto com crianças de sua faixa etária, com garantia de meios e recursos que irão suprir os seus impedimentos à aprendizagem e ao seu desenvolvimento afetivo e cognitivo (CASSIANO PV, 2017).

Sendo reconhecida como um meio de comunicação legal pelo Decreto 5.626/2005, que por sua vez vem regulamentar a Lei 10.436/2002, a Língua Brasileira de Sinais (LIBRAS) é caracterizada como uma língua visuo-espacial utilizada pelas comunidades surdas do Brasil. No início dos anos 80 , os primeiros trabalhos que eram focados nessa temática tinham como preocupação estudar e comprovar que a LIBRAS é, de fato, uma língua natural, da mesma forma que as línguas orais. Assim, é importante destacar que ela não pode ser vista como uma versão manual do português, visto que possui gramática própria e independente (PAIVA FAS, et. al., 2018).

A Lei 10.436/2002 e o Decreto n. ${ }^{\circ} 5.626 / 2005$ são considerados os dois principais documentos que objetivam garantir os direitos das pessoas surdas, com destaque para a área da educação. Em conjunto, elas favoreceram ações desenvolvidas pela comunidade surda em todo o Brasil na luta pela efetivação dos dispositivos propostos e pela garantia dos direitos apresentados (CASSIANO PV, 2017).

A Política Nacional de Educação atualmente estabelece que deve haver a inclusão, defendendo a presença dos alunos na rede regular de ensino, devendo as escolas se organizarem para recebê-los, assegurando também as condições mínimas necessárias para uma educação de qualidade. Uma educação bilíngue deve ser ofertada para os alunos surdos, onde LIBRAS e Português convivam no mesmo espaço, com funções e usos diferentes (BRASIL, 2005; BRASIL, 2008; ALBRES NA e RODRIGUES CH, 2018). 
Alguns profissionais que estão diretamente associados com a educação de surdos, compreendendo as especificidades linguísticas e socioculturais destes: os professores bilíngues que irão atuar na educação infantil e nos primeiros anos do ensino fundamental e para o ensino do Português como segunda língua; os professores de LIBRAS; e os tradutores e intérpretes de LIBRAS para o Português (ALBRES NA e RODRIGUES $\mathrm{CH}, 2018$ ).

Diante dessa perspectiva da inclusão escolar, a educação de surdos passa a acontecer em escolas regulares, onde 0 aluno tem contato com os conhecimentos científicos, que Ihes são apresentados pelo professor de ciências, em língua portuguesa. Assim, o aluno surdo que não utiliza essa língua (a portuguesa), necessitará da atuação de um intérprete de LIBRAS (OLIVEIRA WD e BENITE AMC, 2015).

Umas das políticas mais recentes é a Política Nacional de Educação Especial na Perspectiva da Educação Inclusiva, que veio para consolidar o direito de todos ao ensino regular. Ela tem como eixo orientador a concepção da educação inclusiva como uma ação de cunho político, cultural, social e também pedagógico, que se realiza com o objetivo de defender o direito de todos os docentes de estarem juntos, participando do processo de de aprendizado, sem discriminações (BRASIL, 2008).

Paralelamente, o Plano Nacional dos Direitos da Pessoa com Deficiência (Plano Viver sem Limite), tem como finalidade promover o exercício pleno dos direitos dos deficientes, em igualdade com os demais, através da integração e da articulação de políticas, programas e ações voltadas diretamente à essa parcela da população (BRASIL, 2011).

O Plano Nacional de Educação (PNE) (Lei 13.005/2014), em sua Meta número 04, aborda a universalização de acesso à educação para as pessoas com deficiência, com transtornos globais do desenvolvimento e com altas habilidades ou superdotação, reiterando que para os alunos surdos deve haver a contratação de tradutores e intérpretes de LIBRAS, guias-intérpretes para os surdoscegos, professores de LIBRAS (prioritariamente surdos) e professores bilíngues (BRASIL, 2014).

Este trabalho justifica-se pela necessidade de se fomentar discussões sobre a inclusão do aluno surdo no sistema de ensino. Assim, a questão norteadora deste trabalho foi: "Como se dá a inclusão do aluno surdo nas instituições de ensino?". O objetivo principal deste trabalho é verificar como se dá a inclusão do aluno surdo nas instituições de ensino. Para os alcances dos objetivos propostos sera realizada uma revisão narrativa da literatura.

\section{REVISÃO BIBLIOGRÁFICA}

\section{A Língua Brasileira de Sinais (LIBRAS)}

As dificuldades vivenciadas pela deficiência auditiva fizeram com que os surdos compreendessem e interagissem com o mundo através de experiências visuais, culminando com o surgimento de uma cultura própria, manifestada pelo uso de uma língua gestual-visual. A incorporação desta língua gestualvisual é vital para que sejam realizadas à expansão das relações interpessoais dos surdos, que por sua vez irão constituir o funcionamento nas esferas afetiva e cognitiva e irão fundamentar a construção da subjetividade (MARQUES HCR, et al., 2013).

A Língua Brasileira de Sinais (LIBRAS), diferente da mímica, se constitui uma língua natural, possuindo estrutura gramatical própria em todos os seus níveis fonológico, morfológico, sintático, semântico e sendo capaz de transmitir conceitos concretos e abstratos por meio do canal essencialmente visual (LEVINO DA, et al., 2013).

Importante destacar que nela a expressão irá se dar através de sinais, e que estes possuem cinco parâmetros principais para a realização do sinal: a configuração de mão, o ponto de articulação, a orientação, o movimento e a expressão facial/corporal (MARQUES HCR, et al., 2013).

De acordo com Brito LF (1995), a estrutura da LIBRAS possui parâmetros primários e secundários, que irão se combinam de forma sequencial e/ou simultânea. Isso significa dizer que ela é mais que sinais representados graficamente, a Libras não pode ser reduzida a representações gráficas, ela é espaço-visual, ela é uma língua. 


\section{A LIBRAS enquanto agente de inclusão do aluno surdo nas instituições de ensino}

O processo de aprendizagem e de desenvolvimento do aluno surdo obrigatoriamente deveriam estar atrelados à aprendizagem pela LIBRAS: a língua natural dos surdos e a de sua comunidade. Ela possibilita a interpretação e a interação com o outro, sendo completamente distinta da maioria dos ouvintes e fundamental para inserção do surdo nos processos dialógicos dos meios sociais em que vivem, mas, ao mesmo tempo, ajuda na definição da sua construção identitária (SILVA CM, et al., 2018).

Percebe-se que a Língua de Sinais vem sendo reconhecida como caminho essencial para que haja uma real mudança nas condições ofertadas pelas instituições de ensino no atendimento aos alunos surdos, não podendo ser ignorada no processo de ensino e de aprendizagem do educando, se constituindo em um verdadeiro alicerce para a comunicação (CASSIANO PV, 2017).

Devido à ausência da comunicação oral por parte dos surdos, uma das propostas para viabilização da comunicação é que os profissionais da educação, em especial aqueles que atuam diretamente com o surdo, sejam capacitados para se comunicarem de maneira mais eficiente.

Essa capacitação se concretizaria com o oferecimento de cursos de LIBRAS para todos os profissionais, para que estes tenham um mínimo de entendimento necessário para uma comunicação eficaz (SOUZA MT e PORROZZI R, 2009).

Ainda segundo Souza MT e Porrozzi R (2009), uma outra justificativa para a relevância (desde a recepção até os professores) é pelas necessidades de comunicação entre os profissionais e os alunos surdos, favorecendo a interação e troca de informações, possibilitando uma relação mais humana e resolutiva, atendendo a todos conforme suas particularidades, especificidades, expectativas e necessidades.

\section{Legislação que permeia as práticas de inclusão do surdo nas instituições de ensino}

Promulgada em 1989, a lei 7.853 trata do apoio às pessoas de deficiência e a sua integração social. Já no seu $1^{\circ}$ artigo, a lei diz deverão ser considerados os valores básicos da igualdade de tratamento e de oportunidade, de justiça social e de respeito à dignidade da pessoa humana, do bem-estar, e outros, conforme já indicados na Constituição Federal.

O seu artigo $2^{\circ}$ vem estabelecer as obrigações dos órgãos públicos, para que assegurem ao deficiente 0 pleno exercício dos seus direitos básicos: "educação, saúde, trabalho, lazer, previdência social, amparo à infância e à maternidade, propiciando seu bem-estar pessoal, social e econômico" (BRASIL, 1989).

Não se pode falar de legislação envolvendo a comunidade surda sem mencionar a Lei 10.436/2002 e o Decreto $5.626 / 2005$, sendo ambos os principais marcos da luta pelos direitos da pessoa surda. A lei em questão trata da Língua Brasileira de Sinais (LIBRAS), dizendo (BRASIL, 2002):

"Art. $1^{\circ}$ É reconhecida como meio legal de comunicação e expressão a Língua Brasileira de Sinais - Libras e outros recursos de expressão a ela associados. Parágrafo único. Entende-se como Língua Brasileira de Sinais - LIBRAS a forma de comunicação e expressão, em que o sistema linguístico de natureza visual-motora, com estrutura gramatical própria, constituem um sistema linguístico de transmissão de ideias e fatos, oriundos de comunidades de pessoas surdas do Brasil. Art. $4^{\circ} \mathrm{O}$ sistema educacional federal e os sistemas educacionais estaduais, municipais e do Distrito Federal devem garantir a inclusão nos cursos de formação de Educação Especial, de Fonoaudiologia e de Magistério, em seus níveis médio e superior, do ensino da Língua Brasileira de Sinais - Libras, como parte integrante dos Parâmetros Curriculares Nacionais - PCNs, conforme legislação vigente".

O capítulo $5^{\circ}$ da Lei de Diretrizes e Bases da Educação Nacional (LDB) trata da Educação Especial e vem com o seguinte texto: 
"Entende-se por educação especial, para os efeitos desta Lei, a modalidade de educação escolar, oferecida preferencialmente na rede regular de ensino, para educandos portadores de necessidades especiais. $\S 1^{\circ}$ Haverá, quando necessário, serviços de apoio especializado, na escola regular, para atender às peculiaridades da clientela de educação especial." (BRASIL, 1996, p.23)

Não se pode deixar de citar o Decreto 3.298 de 20 de dezembro de 1.999 que veio para regulamentar a Lei 7.853/1989 (dispõe sobre a Política Nacional para a Integração da Pessoa Portadora de Deficiência). De acordo com o decreto, em seu artigo 3 :

"I - deficiência - toda perda ou anormalidade de uma estrutura ou função psicológica, fisiológica ou anatômica que gere incapacidade para o desempenho de atividade, dentro do padrão considerado normal para o ser humano; Il - deficiência permanente - aquela que ocorreu ou se estabilizou durante um período de tempo suficiente para não permitir recuperação ou ter probabilidade de que se altere, apesar de novos tratamentos; e III - incapacidade - uma redução efetiva e acentuada da capacidade de integração social, com necessidade de equipamentos, adaptações, meios ou recursos especiais para que a pessoa portadora de deficiência possa receber ou transmitir informações necessárias ao seu bem-estar pessoal e ao desempenho de função ou atividade a ser exercida" (BRASIL, 1999, p. 1).

Visando promover a acessibilidade das pessoas portadoras de deficiência ou com mobilidade reduzida, a Lei 10.098, em seu artigo 2ํㅡㄹ aborda especificamente as barreiras enfrentadas nos processos de comunicação e de informação:

"[...] barreiras nas comunicações e na informação: qualquer entrave, obstáculo, atitude ou comportamento que dificulte ou impossibilite a expressão ou o recebimento de mensagens e de informações por intermédio de sistemas de comunicação e de tecnologia da informação" (BRASIL, 2000, p. 02).

A referida lei (10.098/2000) diz ainda que:

"[...] pessoa com deficiência: aquela que tem impedimento de longo prazo de natureza física, mental, intelectual ou sensorial, o qual, em interação com uma ou mais barreiras, pode obstruir sua participação plena e efetiva na sociedade em igualdade de condições com as demais pessoas" (BRASIL, 2000, p. 2).

A lei 10.098 também faz uma abordagem direta à LIBRAS, quando se trata do processo de comunicação, sendo explícito que este nada mais é do que a interação entre os cidadãos, abrangendo, por sua vez, as línguas, não excluída a

"Língua Brasileira de Sinais, o Braille, o sistema de sinalização ou de comunicação tátil, os caracteres ampliados, os dispositivos multimídia, assim como a linguagem simples, escrita e oral, os sistemas auditivos e os meios de voz digitalizados e os modos, meios e formatos aumentativos e alternativos de comunicação, incluindo as tecnologias da informação e das comunicações" (BRASIL, 2000).

Ainda de acordo com o Decreto, agora numa análise do seu artigo 5ำ é estipulado um prazo a partir de um ano de sua publicação para que o Sistema Único de Saúde (SUS) e as empresas que possuem concessão ou permissão de serviços públicos de assistência à saúde, garantam aos alunos devidamente matriculados nas redes de ensino da educação básica, a atenção integral à sua saúde, nos diversos níveis de complexidade e de especialidades médicas (BRASIL, 2005).

Em última análise, não se pode deixar de citar a Lei 12.319 / 2010, que regulamenta a profissão de Tradutor e Intérprete de LIBRAS (TILS). De acordo com referida lei, esse profissional será competente para realizar a interpretação das 2 (duas) línguas de forma concomitante / consecutiva, sendo obrigatório que tenha proficiência em tradução e interpretação da LIBRAS e da Língua Portuguesa. Nesse contexto, a formação do TILS será realizada em nível médio, por meio de: 
"I - cursos de educação profissional reconhecidos pelo Sistema que os credenciou; II - cursos de extensão universitária; e III - cursos de formação continuada promovidos por instituições de ensino superior e instituições credenciadas por Secretarias de Educação" (BRASIL, 2010).

\section{A inclusão do aluno surdo nas instituições de ensino e o papel do Intérprete de LIBRAS}

De acordo com Honora M (2014), o registro que se encontra na história da educação de surdos tem seus primórdios no século XII e tende-se a uma concepção dos romanos e gregos que as pessoas deficientes surdas não eram humanas, por não falarem. Entendiam-se que eles não podiam pensar, ou não conseguiam.

Freire P (1997), no seu livro A Pedagogia da Autonomia, destaca a importância de propiciar condições aos educandos em suas socializações com os outros e com o professor, afim de testar a experiência de assumirse como um ser histórico e social, que pensa, que critica, que tem sonhos e opiniões, se comunica e que dá sugestões (FREIRE P, 1997). Cabe ressaltar que esse processo de comunicação anda de mãos dadas com a inclusão.

Atualmente muito tem se falado sobre a política de educação inclusiva contida na LDB de 1996, que visa um único sistema escolar com acesso para todos. Nesse sentido, a inclusão escolar trata da obrigatoriedade que as escolas públicas tem de oferecer o acesso à educação de qualidade para todos os alunos, respeitando as suas particularidades, sejam elas étnicas, religiosas, culturais e/ou orgânicas e psicológicas (LOPES ES, et al., 2016; RIBEIRO CB, 2014).

Um indicador de que a inclusão tem atingido o público-alvo é o crescente número de alunos matriculados nas escolas. Entretanto, este aumento não significa necessariamente o sucesso da inclusão educacional, visto que existe uma defasagem escolar, em termos de aprendizagem, constatada por diversos estudos sobre os alunos com necessidades educacionais especiais (KASSAR MDCM, 2011; LOPES ES, 2016; SILVA CM, et al., 2013).

Os processos de inclusão ainda estão em vias de implantação e de adaptação e também passam por diversas dificuldades, cabendo à escolar não apenas de aceitar a matrícula do aluno, mas acolher as particularidades deles enquanto socialmente minoritários, garantindo-lhes uma aprendizagem efetiva. Simplesmente o fato de estar na escola, junto com outros estudantes, não garante a efetividade da inclusão. Esse cenário da vivência escolar tem sido chamado de in/exclusão (MULLER JI e MIANES FL, 2016).

Conforme diz Miller Jl e Mianes FL (2016), pensar em uma escolar para todos é algo utópico, não sendo tão simples a promoção de uma educação que tenha como norte os princípios da igualdade sem que se leve em consideração as diferenças existentes, de forma que ela não seja mascarada pelo discurso simplório da diversidade. É imprescindível refletir sobre as diferenças que existem entre os sujeitos, que irão se relacionar e aprender de formas diferentes.

Nesse contexto da inclusão, os estudos da Tradução e Interpretação de Língua de Sinais surgem no país a partir do reconhecimento da LIBRAS enquanto língua, através da Lei 10.423/2002 e, posteriormente, com a regulamentação da profissão de Tradutor e Intérprete da Língua Brasileira de Sinais (ILS), através da Lei 12.319/2010 (FOMIN C, 2018).

Nos padrões atuais o profissional ILS tem como foco das suas atividades a promoção da comunicação entre falantes de duas línguas diferentes, sendo uma auditivo-oral e a outra viso-gestual, favorecendo a comunicação entre eles. Essas línguas são denominadas Língua Fonte (LF), língua na qual o intérprete ouve ou vê e que faz a tradução e interpretação para a outra língua, denominada Língua Alvo (LA). Assim, traduzir e interpretar são atividades com naturezas distintas, onde o uso da palavra tradutor é feito de forma generalizada, incluindo também o termo interpretação. (SANTOS KAS e LACERDA CBF, 2018)

O ILS recebe a informação na LF e escolhe como replicar essa informação na LA. Não se trata de escolhas simples, visto que não são apenas palavras pronunciadas, mas ideias e opiniões. Nem sempre são encontrados referentes diretos de uma língua para a outra, e por isso é necessário interpretar efetivamente o 
significado do que foi dito (LF), buscando manter o sentido o mais próximo possível na outra língua (LA) (SANTOS KAS e LACERDA CBF, 2018).

Assim, a interpretação será a somatória do conhecer bem o tema e do saber enunciar. Esse conhecimento sobre o que está sendo trabalhado confere conforto ao intérprete durante sua atuação, fazendo com o que o trabalho flua de forma mais facilitada. O tema conhecido, por sua vez, reassegura a prática do intérprete, que fica menos preocupado e atua com mais segurança (SANTOS KAS e LACERDA CBF, 2018).

A responsabilidade dada ao intérprete ultrapassa a prática de traduzir os conteúdos, haja vista que o objetivo deve ser de certificação sobre a compreensão do aluno surdo. É necessária uma sintonia entre a interpretação que está sendo realizada e o trabalho dos demais profissionais da equipe educativa, objetivando promover não apenas a escolarização, mas garantindo a aceitação do aluno surdo na sala de aula e em todo o universo escolar (SILVA CM, et al., 2018).

\section{CONSIDERAÇÕES FINAIS}

É notório que muitos foram os avanços para a inclusão dos surdos no contexto social, em especial o educacional. Esses avanços irão passar, obrigatoriamente, pela área da saúde e da educação. Porém, sabemos que tais mudanças irão ocorrer de forma sistemática e exigirão esforços para a divulgação e manutenção da cultura surda. Nossa sociedade, infelizmente, ainda é dominada por preconceitos culturais que foram herdados do passado e que até hoje fazem com que as pessoas surdas sejam excluídas. É importante destacar que a partir o reconhecimento da LIBRAS como língua no país a comunidade surda teve um relativo incremento de espaço na sociedade.

\section{REFERÊNCIAS}

1. ALBRES NA, RODRIGUES CH. As funções do intérprete educacional: entre práticas sociais e políticas educacionais. Revista Bakhtiniana, 2018; 13(03): 16-41.

2. AMESTOY SC, et al. Produção científica sobre liderança no contexto da enfermagem Revista Escola de Enfermagem. USP, São Paulo, 2012; 46(1): 227-233.

3. BRAIT B. Olhar e ler: verbo-visualidade em perspectiva dialógica. Bakhtiniana: Revista de Estudos do Discurso, 2013; 8(2): 43-66.

4. BRASIL. Constituição da República Federativa do Brasil. Brasília / DF, 1988.

5. BRASIL. Decreto 3.298 de 20 de dezembro de 1.999. Regulamenta a Lei 7.853/1989 e dispõe sobre a Política Nacional para a Integração da Pessoa com Deficiência. 1999.

6. BRASIL. Decreto 5.626 de 22 de dezembro de 2005. Regulamenta a Lei 10.436 de 204 de abril de 2002. Dispõe sobre a Língua Brasileira de Sinais - Libras, e o artigo 18 da Lei 10.098 de 19 de dezembro de 2000.

7. BRASIL. Decreto ํ․ 7.612, de 17 de novembro de 2011. Institui o Plano Nacional dos Direitos da Pessoa com Deficiência - Plano Viver sem Limite.

8. BRASIL. Lei 10.098 de 19 de dezembro de 2000. Estabelece normas gerais e critérios básicos para a promoção da acessibilidade das pessoas portadoras de deficiência ou com mobilidade reduzida.

9. BRASIL. Lei 10.436 de 204 de abril de 2002. Dispõe sobre a Língua Brasileira de Sinais - Libras e dá outras providências.

10. BRASIL. Lei 12.319 de $1^{\circ}$ de setembro de 2010. Regulamenta a profissão de Tradutor e Intérprete de LIBRAS.

11. BRASIL. Lei 7.853 de 24 de outubro de 1989. Dispõe sobre o apoio às pessoas portadoras de deficiência, sua integração social, sobre a Coordenadoria Nacional para Integração da Pessoa Portadora de Deficiência - Corde, institui a tutela jurisdicional de interesses coletivos ou difusos dessas pessoas, disciplina a atuação do Ministério Público, define crimes, e dá outras providências.

12. BRASIL. Lei 9.394 de 20 de dezembro e 1996. Estabelece as diretrizes e bases da educação nacional.

13. BRASIL. Lei no. 13.005, de 25 de junho de 2014. Aprova o Plano Nacional de Educação PNE e dá outras providências.

14. BRASIL. Política Nacional de Educação Especial na Perspectiva da Educação Inclusiva. MEC/SEESP, 2008.

15. BRASIL. Decreto 5.626 de 22 de dezembro de 2005. Regulamenta a Lei 10.436 de 204 de abril de 2002.

16. BRITO LF. Por uma gramática de línguas de sinais. Rio de Janeiro: Tempo Brasileiro: UFRJ, 1995.

17. CASSIANO PV. O surdo e seus direitos: os dispositivos da Lei 10.436 e do Decreto 5.626 Centro Virtual de Cultura Surda. Revista Virtual de Cultura Surda, 2017; 21(01-28).

18. FERNANDES S, MOREIRA LC. Políticas de educação bilíngue para surdos: o contexto brasileiro. Educar em Revista, 2014; 02(1): 51-69.

19. FOMIN C. Verbo-visualidade e seus efeitos na interpretação em Libras no teatro. Bakhtiniana, São Paulo, 2018; 13(3): 142-164.

20. FREIRE P. Pedagogia da autonomia. São Paulo: Editora Paz e Terra, 1997.

21. HONORA M. Inclusão educacional de alunos com surdez: concepção e alfabetização: ensino fundamental, 1 ciclo/ Marcia Honora. - São Paulo: Cortez, 2014. 
22. KASSAR MDCM. Educação especial na perspectiva da educação inclusiva: Desafios da implantação de uma política nacional. Educar e Revista, 2011; (41): 61-79.

23. LEVINO DA, et al. Libras na Graduação Médica: o Despertar para uma Nova Língua. Revista Brasileira de Educação Médica, 2013; 37(2): 291-297.

24. LOPES ES, et al. Políticas públicas e organizações na educação do surdo. Revista de Psicologia, 2016; 10(32): 228244.

25. MARQUES HCR, et al. O ensino da língua brasileira de sinais na educação infantil para crianças ouvintes e surdas: considerações com base na psicologia histórico-cultural. Revista Brasileira de Educação Especial, 2013; 19(4): 503518.

26. MULLER JI, MIANES FL. Narrativas autobiográficas de surdos ou de pessoas com deficiência visual: análise de identidades e de representações. Rev. bras. Estud. pedagog. (online), Brasília, 2016; 97(246): 387-401.

27. OLIVEIRA WD, BENITE AMC. Aulas de ciências para surdos: estudos sobre a produção do discurso de intérpretes de LIBRAS e professores de ciências. Revista Ciências e Educação, 2015; 21(2): 457-472.

28. PAIVA FAZ, et al. Análise do papel das expressões não manuais na intensificação em libras. Revista Delta, 2018; 34(4): 1135-1158.

29. RIBEIRO CB. Narrativas e processos de desenvolvimento bicultural: trajetórias escolares de surdos jovens e adultos (Dissertação de Mestrado). Universidade de Brasília, DF, Brasil, 2014.

30. SANTOS KAS, LACERDA CBF. O intérprete de libras-português no contexto de conferência: reflexões sobre sua atuação. Bakhtiniana, São Paulo, 2018; 13(2): 63-82.

31. SEVERO C. Políticas linguísticas e questões de poder. Revista Alfa, 2013; 57(451-473).

32. SILVA CM, et al. Inclusão Escolar: Concepções dos Profissionais da Escola sobre o Surdo e a Surdez. Psicologia: Ciência e Profissão, 2018; 38(3): 465-479.

33. SILVA CM, et al. Inclusão e processos de escolarização: Narrativas de Surdos sobre estratégias pedagógicas docentes. Psicologia em Estudo, 2013; 19(2), 261-271.

34. SOUZA MT, PORROZZI R. Ensino de Libras para profissionais de saúde: uma necessidade premente. Revista Práxis, 2009; 01(2), 43-46. 